\title{
LA POSICIÓN JURÍDICA DE LA MUJER A TRAVÉS DE LAS REFORMAS DEL DERECHO DE FAMILIA
}

MARÍA LUISA VALLÉS AMORES

Universidad de Alicante

\section{INTRODUCCIÓN}

Durante los días 17, 18 y 19 de noviembre de 2004, el Seminario Universitario sobre los Derechos de las Mujeres, del Área de Derecho Constitucional de la Facultad de Derecho de la Universidad de Alicante, organizó un Curso, "Mujeres y Derecho", cuya finalidad consistió en poner de manifiesto que, a pesar de los cambios legislativos producidos desde la aprobación de la Constitución de 1978, para llegar a la igualdad legal entre hombres y mujeres, la realidad nos muestra que las diferencias de género producen desvíos significativos en la creación, interpretación y aplicación del Derecho.

Agradeciendo muy sinceramente mi participación en dicho curso mediante la ponencia, "La posición jurídica de la mujer a través de las reformas del Derecho de familia», mi colaboración consistió en una exposición, dentro del contexto del Derecho Civil y concretamente en el ámbito del Derecho de Familia, del desarrollo evolutivo de la situación jurídica de la mujer, con independencia de su situación matrimonial, en el Derecho de Familia desde la redacción originaria del Código civil1.

Antes de comenzar con la exposición quisiera puntualizar dos cuestiones. En primer lugar debo advertir que la ponencia no tiene la finalidad de analizar la problemática planteada como consecuencia de la situación jurídica en la que se encontraba la mujer según la legalidad vigente en cada momento histórico; su objetivo radica en una mera exposición de la normativa reguladora en cada época en la que se ha llevado a cabo una reforma del Código civil en esta temá-

1. Para obtener una visión de los antecedentes prelegislativos, precedentes legales así como de la posición de la jurisprudencia de la época, vid. SCAEVola, Q. M.: Código Civil, tomos correspondientes, $5^{\mathrm{a}}$ ed. coment. por ORTEGA LORCA, F.: Madrid, Instituto Editorial Reus, 1942.

Feminismo/s, 8, diciembre 2006, pp. 115-129 
tica ${ }^{2}$. Por otra parte, quiero hacer constar que si bien de la exposición pudiera deducirse mi rechazo hacia nuestra legislación anterior, inspirada en los principios dominantes en cada momento, no es esa mi pretensión, al menos en este momento, más bien quiero poner de manifiesto mi satisfacción hacia una evolución en la posición jurídica de la mujer, demandada por nuestra sociedad.

De los diversos sectores del Derecho Civil, es el Derecho de familia el que se ha visto sometido en las últimas décadas a reformas más profundas. El fenómeno es particularmente ostensible en nuestro país como consecuencia de dos factores fundamentales desde el punto de vista técnico. En primer lugar, la redacción originaria del Código civil de 1889, inspirado en criterios propios del momento codificador, que pueden sintetizarse en el carácter patriarcal de la familia, la sumisión de la mujer a la autoridad del marido y la radical discriminación entre los hijos legítimos e ilegítimos. El segundo factor, a que aludía, se refiere a la aprobación y promulgación de la Constitución de 1978, consagrando principios relativos a la dinámica familiar, absolutamente contradictorios con los inspiradores del Código civil.

En este sentido, y en relación a la posición jurídica de la mujer, la Constitución establece la absoluta igualdad jurídica de todos los españoles ante la Ley sin que pueda prevalecer discriminación, entre otras causas, por razón de sexo (artículo 14.1) así como entre el marido y la mujer respecto al matrimonio (artículo 32.1).

Tales principios han sido plasmados fundamentalmente mediante las reformas del Código civil operadas por una legislación que ha supuesto de facto la construcción o instauración de un nuevo Derecho de familia, asentado, en numerosísimos aspectos, en presupuestos contrarios de lo establecido en la redacción originaria del Código civil.

\section{REFERENCIA A LA SINGULAR POSICIÓN JURÍDICA DE LA MUJER RESPECTO A LA DEL VARÓN EN RELACIÓN A LA EDAD Y AL MATRIMONIO}

En el Código civil, el sexo ha sido considerado tradicionalmente como una de las causas modificativas de la capacidad de obrar, en el sentido de que las diferencias existentes entre el hombre y la mujer hacían aconsejable restringir la libre iniciativa de esta última. En cambio, el sexo masculino nunca ha supuesto históricamente restricción alguna de las posibles actividades del hombre. La consecuencia de ello se tradujo en que la redacción originaria del Código civil de 1889, reflejaba algo tan evidente como que durante siglos, la mujer ha

2. La problemática jurídica planteada como consecuencia de la distinta posición jurídica de la mujer respecto al varón, resulta tan diferente y diversa en cada uno de los ámbitos en los que se producía, que excede de nuestras pretensiones en este momento. En cualquier caso, respecto a los comentarios a las diferentes reformas en esta temática, vid. ALVADALEJO, M. (dir.): Comentarios al Código Civil y Compilaciones forales, (arts. corresp.), Madrid, ediciones de 1978, 1982 y 2000 y BerCovitz, R. (coord..): Comentarios a las reformas del Código Civil (arts. corresp.), Madrid, Edersa, 1977 y 1993. 
desempañado un papel secundario en la sociedad y que dicha realidad ha sido siempre objeto de diverso tratamiento por las normas jurídicas.

En base a esta consideración de la mujer, por la normativa reguladora, la mayoría de edad, que se adquiría a los 23 años para ambos, quedaba limitada en su ejercicio para la mujer, puesto que hasta el cumplimiento de los 25 años, las hijas de familia mayores de edad, no podían dejar la casa paterna sin licencia del padre o de la madre en cuya compañía vivían, salvo para ingresar en convento, contraer matrimonio o cuando cualquiera de los padres hubieran contraído ulteriores nupcias ${ }^{3}$. La Ley de 13 de diciembre de 1943, si bien rebajó la mayoría de edad a 21 años, mantuvo la misma situación. Fue la Ley 31/1972, de 22 de julio la que suprimió la restricción de la mujer no casada, respecto a su autonomía como persona, para poder abandonar voluntariamente el domicilio paterno si deseaba vivir fuera del hogar familiar.

En relación a la apuntada restricción en la mujer, curiosamente hasta el año 1981-reforma del Código civil de suma importancia para la mujer y a la que me referiré posteriormente -, el artículo 46 del Código establecía que "corresponde otorgar la licencia para el matrimonio de los hijos legítimos al padre, faltando éste o hallándose impedido, en orden sucesivo, a la madre, al abuelo paterno, al materno, a las abuelas paterna, materna, y en su defecto al Consejo de familia». El precepto en cuestión pone de manifiesto la autoridad patriarcal hasta tiempos muy recientes, puesto que puede observarse la forma en que la mujer (madre, abuela) era relegada al último lugar. No sólo necesitaba autorización, siendo mayor de edad, para abandonar el domicilio paterno; también la licencia se otorgaba con una prioridad por parte del varón.

En cualquier caso, más desolador resultaba el panorama de la mujer casa$\mathrm{da}$, puesto que estaba sometida a la autoridad marital (artículo 57 C.c.) ${ }^{4}$. En consecuencia, no solo le pesaba el deber unilateral de obediencia a su marido; también estaba obligada a seguir el domicilio y la nacionalidad de su cónyuge (artículos 58 y 21 del Código civil) $)^{5}$. Esta posición de sumisión producía que en caso de infidelidad conyugal, la conducta de la mujer, independientemente de su consideración penal, a tenor del artículo 105 del Código civil, fuera discriminatoria respecto a la infidelidad del varón, puesto que el precepto reseñado disponía que «Las causas legítimas del divorcio son: $1^{\circ} \mathrm{El}$ adulterio de la mujer, en todo caso, y el del marido cuando resulte escándalo público o menosprecio de la mujer». En virtud de esta normativa, el varón que no cometiese escándalo público o no causara menosprecio a su mujer, como consecuencia del incumpli-

3. Artículo 321 del Código civil en su redacción originaria.

4. Artículo 57 del Código civil en su redacción originaria: «El marido debe proteger a la mujer y ésta obedecer al marido».

5. Artículo 58 del Código civil en su redacción originaria: «La mujer está obligada a seguir a su marido donde quiera que fije su residencia. Los Tribunales, sin embargo, podrán con justa causa eximirla de esta obligación cuando el marido traslade su residencia a ultramar o a país extranjero». Desaparece esta restricción por Ley 14/1975, de 2 de mayo. 
miento de su deber de fidelidad, no tenía el temor de ver disuelto el matrimonio en contra de su voluntad.

En base a las consideraciones apuntadas, la propia normativa imponía como conducta socialmente aceptable «la relación extramatrimonial discreta del varón", sin embargo, la locución, "en todo caso», referida a la mujer, la hacía merecedora de culpabilidad sin ninguna duda.

Otra consecuencia práctica, derivada de la autoridad marital, se traducía en la ineludible necesidad de licencia de su marido para la realización de diversos actos. Baste como ejemplo que para aceptar una herencia que a ella le hubiera correspondido necesitaba la anuencia de su esposo, puesto que el artículo 1263.3 del Código civil prohibía a las mujeres casadas prestar su consentimiento en los casos expresados en la Ley, siendo uno de ellos la aceptación de la herencia a su favor con su sola declaración de voluntad. Tampoco podía, a tenor de los artículos 6 a 9 del Código de comercio, ejercer el comercio sin licencia marital.

En síntesis, el marido era el representante de la mujer a tenor de lo dispuesto en el artículo 60 del Código civil ${ }^{6}$.

Con semejantes planteamientos legales, la mujer que conservara su soltería, una vez que cumplía la edad de 25 años, de alguna manera se colocaba en una posición de cierta autonomía personal; ahora bien, con el reproche social por conservar su soltería, puesto que no había logrado un marido. Si la mujer soltera no había cumplido los 25 años, su estado jurídico quedaba reservado a la sumisión patriarcal; situación que no se producía en el caso del varón ${ }^{7}$. Si bien, al cumplir la referida edad, podía considerarse que su posición jurídica no distaba demasiado de la del varón, salvo en determinadas cuestiones a las que más adelante haré referencia, en el supuesto de que optara por contraer matrimonio, se le negaba su capacidad y autonomía como persona, puesto que debía obediencia y sumisión a su marido.

Ley de 2 de mayo de 1975, adelantándose, aunque no fuera este su propósito, a nuestro Texto Constitucional, tuvo a bien suprimir estos deberes unilaterales, sustituyéndolos por derechos y deberes recíprocos de respeto y protección.

La referida Ley suprimió asimismo la marginación que pesaba sobre la mujer casada respecto a la administración y disposición de los bienes matrimoniales,

6. Artículo 60 del Código civil en su redacción originaria: «El marido es el representante de su mujer. Ésta no puede, sin su licencia, comparecer en juicio por sí o por medio de Procurador». Desaparece esta restricción por Ley 14/1975, de 2 de mayo.

7. Debe observarse un dato curioso, constatado popularmente, en los supuestos de separación y posteriormente- a partir de la Ley 30/1981, de 7 de julio- de divorcio. Las mujeres reconocen haber contraído matrimonio, en numerosísimas ocasiones, impulsadas por la necesidad de salir del sometimiento paterno; sin embargo, la Ley les obligaba, entonces, al sometimiento a la autoridad marital mientras duraba el matrimonio. 
puesto que dicha esfera quedaba, hasta ese momento, reservada a la iniciativa del marido a tenor de lo dispuesto en el artículo 62 del Código civil ${ }^{8}$

\section{POSICIÓN JURÍDICA DE LA MUJER EN CUANTO A LA PATRIA POTESTAD Y TUTELA}

Si bien, como ha quedado constatado hasta el momento, la situación marginal de la mujer casada respecto a sus bienes privativos y matrimoniales producía una considerable limitación en su autonomía personal, todavía, más grave resultaba que la titularidad de la patria potestad correspondiera al marido, y sólo en su defecto a la mujer según disponía el artículo 154 del Código civil. En este contexto de limitación de la autonomía de la mujer, el artículo 237 del mismo Texto legal la imposibilitaba para ser tutora; situación que persiste hasta su supresión por la Ley 14/1975, de 2 de mayo.

Curiosamente, entre las personas que la Ley consideraba no aptas para desempeñar la tutela, además de las mujeres, se encontraban una serie de personas cuya conducta o modo de vivir era perjudicial para el pupilo, o bien en razón a su situación les impediría atender a las necesidades del tutelado9.

La circunstancia de que la patria potestad la ostentase el marido, producía consecuencias gravísimas no sólo para la mujer, también para los hijos menores de edad, puesto que el Código civil disponía que si la esposa enviudaba y contraía nuevo matrimonio, perdía la patria potestad sobre sus hijos, salvo que el difunto marido (padre de los hijos) hubiera previsto expresamente en testamento que su viuda contrajera matrimonio, habiendo ordenado, en tal caso, que conservase y ejerciese la patria potestad sobre sus hijos a tenor de lo dispuesto en el artículo 168 del Código. Sólo si volvía a enviudar de este segundo matrimonio, recuperaba la patria potestad sobre todos los hijos no emancipados según disponía el artículo 172 del mismo Texto lega ${ }^{10}$.

8. Artículo 62 del Código civil en su redacción originaria: «Son nulos los actos ejecutados por la mujer contra lo dispuesto en los artículos anteriores, salvo cuando se trate de cosas que por su naturaleza estén destinadas al consumo ordinario de la familia, en cuyo caso, las compras hechas por la mujer serán válidas. Las compras de joyas, muebles y objetos preciosos, hechas, sin licencia del marido, sólo se convalidarán cuando éste hubiere consentido a su mujer el uso y disfrute de tales objetos».

9. El artículo $237.7^{\circ}$ C.c., en su redacción originaria, disponía que «no pueden ser tutores ni protutores, las mujeres, salvo los casos en que la ley las llama expresamente». El mismo precepto y número se modificó por Ley de 24 de abril de 1958 con objeto de permitir que la mujer pudiera ser tutora, salvo si estaba casada y no había obtenido licencia de su marido. El artículo 237, en los 12 números que imposibilitaba la tutela a las personas reseñadas, incluía además de a las mujeres a los penados por delitos de robo, hurto, corrupción de menores, escándalo público; los condenados a cualquier pena privativa de libertad, mientras estuvieran sufriendo condena; personas de mala conducta o que no tuvieran manera de vivir conocida. La imposibilidad para ser tutores se extendía, asimismo, a otras personas a las que se presumía no poder ocuparse del tutelado: religiosos profesos, extranjeros no residentes en España.

10. Fue la Ley de 24 de abril de 1958 la que suprimió esta injusta normativa para la mujer que le impedía libremente volver a contraer matrimonio, puesto que el precio que debía pagar era la pérdida de la patria potestad, salvo que su difunto marido le hubiera otorgado el pertinente permiso. 
La normativa patriarcal sobre atribución de la patria potestad producía la grave consecuencia, en numerosas ocasiones, de que en los supuestos de separación de los cónyuges, la mujer perdía incluso el derecho de visita respecto de sus hijos $y$, por consiguiente, los menores también quedaban sin poder relacionarse con su madre con las consecuencias perjudiciales para su desarrollo emocional y afectivo. En este sentido, resulta muy significativa la Sentencia del Tribunal Supremo de 9 de junio de 1909 que parte de unas argumentaciones totalmente concordantes con la normativa vigente en la época. En cualquier caso, el Tribunal Supremo parece justificar su decisión en los preceptos reguladores, aunque reconociendo el derecho que por naturaleza la madre debería tener a relacionarse con sus hijos; sin embargo, hace una aplicación de la normativa vigente sin tener en consideración otras circunstancias, imposibilitando con ello el derecho de la madre y sus hijos a poder relacionarse.

En síntesis, los argumentos del Tribunal Supremo son los siguientes:

El Auto de la Audiencia Territoria ${ }^{11}$ atenta en realidad y en el fondo a los derechos y deberes de la patria potestad del marido, obligándolo a separarlos y educarlos contra su voluntad, para lo cual no hay precepto alguno que así lo autorice, ni mucho menos puede fundarse en la razón alegada por su madre, ya que "aun cuando ésta tuviera el derecho de verlos y manifestarle su cariño, eso habría de hacerse y realizarse en cuanto la situación de los cónyuges legalmente reconocida así lo consienta». El Tribunal Supremo sigue considerando: «Es manifiesto el error cometido por el Tribunal sentenciador. Si las decisiones de instancia se inspiran, a lo que parece, en razones humanitarias (madre que probablemente no ejerce ninguna profesión y no puede sufragar el desplazamiento para ver a sus hijos y padre, en cambio, notario, que le permite tener una economía desahogada)".

El Tribunal Supremo, ante el conflicto entre los deseos y propósitos de los progenitores respecto de sus hijos, se inclina a favor de aquel que cuenta con el estricto apoyo legal, a la sazón el artículo 154 del Código civil, estableciendo que "El padre y en su defecto la madre tienen potestad sobre sus hijos legítimos no emancipados». En cualquier caso, como habíamos señalado, el Supremo, no obstante, parece reconocer el derecho de la madre a relacionarse con sus hijos, aunque la dura aplicación de la legalidad vigente le impida, siquiera, poder visitarlos en un colegio elegido por el cabeza de familia.

Debe tenerse en cuenta que en la época en que nos situamos, la mujer, además de la sumisión respecto a su marido, la legalidad vigente la imposibilitaba

11. Los hechos brevemente resumidos son los siguientes: en una separación, la esposa solicita el traslado, a Madrid, de sus hijos a fin de poder visitarlos, puesto que su marido y padre de los menores los había internado en Badajoz con expresa prohibición de que recibieran visitas y correspondencia de su madre. El juzgado requirió al marido (que ejercía de notario en esa localidad y había sido nombrado para Navarra) al objeto de que situara a los hijos en poder de persona o colegio de confianza en Madrid para que pudieran ser visitados por su madre los días festivos; acuerdo confirmado por la Audiencia Territorial de Madrid en auto que recurrió y que fue casado por la citada sentencia del Tribunal Supremo. 
para presentarse, entre otras, a oposiciones al Cuerpo de Notarios y Registradores de la Propiedad, profesión que desempeñaba el marido de la Sentencia comentada en líneas precedentes ${ }^{12}$.

\subsection{La Constitución de la Segunda República}

En la posición jurídica de la mujer se abre un periodo más alentador para ella en la década de los años treinta, puesto que la Constitución de la Segunda República de 9 de diciembre de 1931, sienta como principio a desarrollar la igualdad entre ambos sexos, siendo objeto de consideración expresa en diversos artículos. En concreto, el artículo 25 señalaba que el sexo no podía ser fundamento de ningún privilegio jurídico. Por su parte, el artículo 43 establecía que el matrimonio se fundaba en la igualdad de sexos. En consonancia con tal declaración, la Ley de divorcio de 2 de marzo de 1932, de la Segunda República, suprimió esta drástica situación de atribución de la patria potestad, puesto que dispuso, en el artículo 20/II, que «El cónyuge que no tenga a los hijos menores en su poder, conserva el derecho de comunicar con ellos y vigilar su educación en la forma que determine el Juez, quien adoptará las medidas necesarias para el ejercicio de este derecho".

El artículo 40 de la Constitución Republicana sirvió de punto de partida para establecer, a través de diversos Decretos, algunas conquistas parciales para la mujer, entre las que pueden citarse: poder presentarse a oposiciones al Cuerpo de Notarios y Registradores de la Propiedad (Decreto de 29 de abril de 1931); Cuerpos Técnicos de Prisiones (Decreto 29 octubre de 1931); Secretaría de los Tribunales de Justicia (19 de mayo de 1932); ejercer la profesión de Procurador de los Tribunales.

Con la caída de la República, el Estado se sitúa en una actitud patriarcal y paternalista, ocupando la mujer un papel claramente doméstico, puesto que se consideraba como natural y conveniente para el sexo femenino.

\subsection{La Ley de $\mathbf{2 4}$ de abril de 1958}

Durante el régimen del general Franco, poco a poco, las circunstancias sociológicas -desaparición de prejuicios sociales, entrada masiva de turismo, despegue económico- van determinando nueva legislación tendente a abolir las discriminaciones más evidentes entre el hombre y la mujer; disposiciones legales que tiene por objeto sentar las bases de una equiparación entre varón y mujer de una parte y, de otra, en el ámbito familiar, entre el marido y la mujer.

La reforma llevada a cabo por la Ley de 24 de abril de 1958 tiende a ampliar la capacidad de la mujer ${ }^{13}$. En este sentido y con referencia al derecho de

12. También recaía sobre la mujer la prohibición de poder presentarse a oposiciones a la Secretaría de los Tribunales de Justicia así como, entre otras profesiones, ejercer de Procuradora de los Tribunales.

13. Vid. Batlle Vázouez, M: Observaciones sobre la reforma del Código civil lla Ley de 24 de abril de 1958), Madrid, Instituto Editorial Reus, 1958. 
comunicación de la madre separada respecto a sus hijos -que señalábamos anteriormente- aunque la patria potestad la sigue teniendo el padre y sólo en defecto la madre, el Código civil establece que «El Juez determinará el tiempo, modo y lugar que el cónyuge apartado de los hijos podrá visitarlos y comunicar con ellos».

Se suprime la pérdida de la patria potestad por contraer nuevo matrimonio la mujer (artículo 168 del Código civil); permitiéndosele, a partir de este momento, ser testigo en los testamentos (artículo 681).

Respecto a la tutela, si la mujer conserva su soltería, a partir de este momento, ya no tiene imposibilidad para su ejercicio; sin embargo, si ha contraído matrimonio, necesita, para desempeñar este cargo, autorización marital a tenor de lo dispuesto en el número 7 del artículo 237 del Código civil. En cualquier caso, para el llamamiento al ejercicio de este cargo, todavía, el varón se encuentra en una posición preferente, puesto que el artículo 211 del Código establecía el llamamiento de los varones, para el ejercicio del cargo tutelar, con preferencia al de las mujeres; otorgando, incluso entre los varones, prioridad a los ascendientes de este último y prefiriendo a los hermanos de vínculo sencillo antes que a las hermanas, a las que situaba en el mismo orden con independencia de su vínculo ${ }^{14}$. En cualquier caso, al menos, la reforma, llevada a cabo por la Ley de 24 de abril de 1958, en el ámbito de permisión limitada de la tutela para las mujeres, suprimió el requisito de viudedad en las ascendientes maternas del tutelado que exigía la redacción originaria del Código civil ${ }^{15}$.

Si bien las reformas operadas en el Código civil, por la Ley de 1958 supusieron un considerable avance en la consideración de la autonomía personal de la mujer, la modificación más importante es la que atañe al artículo 1413 del Código civil, que hasta este momento permitía al marido no sólo administrar los bienes comunes de ambos cónyuges (sigue siendo así hasta 1981, puesto que el artículo 1441 permitía no solo que la mujer administrase los bienes comunes cuando fuera tutora de su marido, se hubiera pedido la declaración de ausencia, hubiese sido declarado prófugo por la autoridad militar o rebelde en causa criminal. La misma regla se aplicaba si el marido hubiese abandonado a la familia), también gravarlos o enajenarlos sin consentimiento de la mujer. A partir de esta reforma necesitará su consentimiento.

14. Artículo 211 del Código civil según redacción por Ley de 24 de abril de 1958: «La tutela legítima de los menores no emancipados corresponde únicamente: Primero. Al abuelo paterno y, en su defecto, al materno. Segundo. A las abuelas por el mismo orden. Tercero. Al mayor de los hermanos de doble vínculo, y a falta de éstos, de los consanguíneos o uterinos. Cuarto. A las hermanas por el mismo orden. La tutela de que trata este artículo no tiene lugar respecto de los hijos ilegítimos».

15. Artículo 211 del Código civil en su redacción originaria: La tutela legítima de los menores no emancipados corresponde únicamente: $1^{\circ} \mathrm{Al}$ abuelo paterno. $2^{\circ} \mathrm{Al}$ abuelo materno. $3^{\circ} \mathrm{A}$ las abuelas paterna y materna, por el mismo orden, mientras se conserven viudas. $4^{\mathrm{a}} \mathrm{Al}$ mayor de los hermanos varones de doble vínculo y, a falta de éstos, al mayor de los hermanos consanguíneos o uterinos. La tutela de que trata este artículo no tiene lugar respecto de los hijos ilegítimos». 


\section{EVOLUCIÓN LEGAL EN CUANTO A UNA POSICIÓN MÁS IGUALITARIA DE LA MUJER RESPECTO A LA SITUACIÓN DEL VARÓN EN EL MATRIMONIO}

La evolución hacia una consideración más igualitaria entre la mujer y el varón parece iniciarse en la década de los años setenta. Como consecuencia de esta nueva situación, la Ley 31/ 1972, según señalábamos anteriormente, estableció la mayoría de edad en 21 años para ambos. A partir de este momento, la mujer puede abandonar la casa paterna sin necesidad de contraer matrimonio o ingresar en convento; en consecuencia, siempre que conserve su soltería o se encuentre en estado de viudedad, gozará prácticamente de una posición jurídica equiparable a la del varón en el ámbito del Derecho de Familia, con las salvedades de preferencia del varón en todos los llamamientos que hace el Código civil. En cualquier caso, la mujer casada tardará unos años más en alcanzar esta posición.

\subsection{Ley de 2 de mayo de 1975}

La primera Ley que puede encuadrarse en esta línea evolutiva es, sin duda, la Ley de 2 de mayo de 1975, aunque, tal como se desprende de la presentación del Proyecto de Ley a las Cortes, no tuviera un propósito tan reformista, no obstante, introdujo sustanciales reformas en el Código civil y en el Código de Comercio. Al realizar una nueva regulación del domicilio ${ }^{16}$, la nacionalidad y los derechos y deberes recíprocos de los cónyuges, la mujer, deja de ser considerada como un mero satélite del marido. Como consecuencia de esta reforma, deja de estar supeditada a la eterna licencia marital con las subsiguientes consecuencias que la supresión de la licencia del marido conlleva en el ámbito familiar.

La redacción del originario artículo 64 del Código civil, disponiendo que «la mujer gozará de los honores de su marido, excepto los que fueran estrictamente y exclusivamente personales, y los conservará mientras no contraiga matrimonio", se sustituye por una nueva fórmula acorde con esta nueva concepción más progresista. El novedoso precepto establece el disfrute recíproco para ambos cónyuges de los honores de su consorte.

La mencionada Ley de 1975 produce la ruptura del principio de unidad jurídico familiar en materia de nacionalidad. No ocurrió de la misma forma en materia de vecindad civil. Tuvo que ser la Ley de 15 de octubre de 1990, sobre reforma del Código civil, en aplicación del principio de no discriminación por razón de sexo, la que llevara a cabo la ruptura del principio jurídico familiar en sede de vecindad civil. En este sentido, la Exposición de Motivos de la Ley de 1990 señala que el fundamento de esta Ley consiste en «eliminar las discriminaciones que por razón de sexo aún perduran en la legislación civil y perfeccionar el desarrollo normativo del principio constitucional de igualdad».

16. Artículo 58 del C.c. en su redacción originaria: «La mujer está obligada a seguir a su marido donde quiera que fije su residencia. Los Tribunales, sin embargo, podrán con justa causa eximirla de esta obligación cuando el marido traslade su residencia a ultramar o país extranjero». 
De gran trascendencia resultó la reforma introducida, por la Ley de 2 de mayo de 1975, en el artículo 1387 del Código civil. Hasta este momento, la mujer no podía, sin licencia de su marido, disponer de los bienes parafernales, ni siquiera comparecer en juicio para litigar sobre ellos ${ }^{17}$. La nueva redacción del precepto la habilita para disponer por sí sola de sus bienes propios, salvo que fuera menor de edad, en cuyo supuesto, a tenor de lo dispuesto en el artículo 61, necesitaba el consentimiento de su padre, en su defecto el de su madre y, a falta de ambos, el de su tutor. En este mismo contexto, a tenor de la nueva redacción dada al artículo 1388 del Código civil, la mujer podía comparecer en juicio y litigar sobre los bienes parafernales, suprimiéndose, con esta nueva redacción del precepto, el poder del marido sobre los bienes propios de la mujer ${ }^{18}$.

Un avance considerable y, a la vez, muy significativo de la Ley de 2 de mayo de 1975, consistió en la sustitución de los preceptos, referentes a los derechos y obligaciones entre marido y mujer, por normas que establecían derechos y deberes recíprocos en consonancia con el principio de que el matrimonio no restringe la capacidad de obrar de los cónyuges. En este sentido, se sustituye la redacción del artículo 57 del Código disponiendo que «el marido debe proteger a la mujer, y ésta obedecer al marido", por una nueva redacción en consonancia con principios más igualitarios que constituyen el presupuesto legal. De esta forma, el reseñado precepto se incardina en las nuevas directrices, disponiendo que «el marido y la mujer se deben respeto y protección recíprocos, y actuarán siempre en interés de la familia».

Con independencia de estas modificaciones que supusieron un avance considerable en la posición jurídica de la mujer, dentro del ámbito del Derecho de Familia, todavía, no se llega a una total equiparación, puesto que el Código civil, sigue atribuyendo, al marido, tanto la patria potestad con preferencia sobre la mujer así como la administración de los bienes matrimoniales.

De la misma suerte, sigue vigente con esta normativa la obligación de constituir dote para la mujer. El artículo 1336 del Código civil dispone que «la dote se compone de los bienes y derechos que en este concepto la mujer aporta al matrimonio al tiempo de contraerlo y de los que durante él adquiera por donación, herencia o legado con el carácter dotal». En perfecta concordancia con esta obligación, el Código civil, en el artículo $1340^{19}$, obligaba a los padres a dotar a

17. Artículo 1387 del Código civil en su redacción originaria: «La mujer no puede, sin licencia, de su marido, enajenar, gravar ni hipotecar los bienes parafernales, ni comparecer en juicio para litigar sobre ellos, a menos que sea judicialmente habilitada al efecto».

18. El artículo 1388 del C.c. en su redacción originaria disponía que «cuando los parafernales, cuya administración se reserva la mujer, consistan en metálico o efectos públicos o muebles preciosos, el marido tendrá derecho a exigir que sean depositados o invertidos en términos que hagan imposible la enajenación o pignoración sin su consentimiento».

19. Artículo 1340 del C.c. según redacción por Ley de 24 de abril de 1958: «el padre o la madre, o el que de ellos viviese, están obligados a dotar a sus hijas legítima, fuera del caso en que necesitando éstas la licencia de aquéllos para contraer matrimonio con arreglo a la ley, se casen sin obtenerla ni obtener tampoco la autorización equivalente, conforme al artículo 49 de este Código". 
sus hijas legítimas cuando contraían matrimonio. El marido, por supuesto, era el administrador y usufructuario de la dote.

La situación de la mujer respecto a la tutela persistió en cuanto a una ostensible discriminación en relación al varón; correspondiendo su ejercicio, en primer lugar al abuelo paterno y en su defecto al materno, ocupan el segundo puesto, las abuelas, en tercer lugar corresponde su ejercicio a los hermanos de doble vínculo, a continuación los de vínculo sencillo, situándose en último lugar las hermanas todas por igual. En este contexto, debo hacer constar que a pesar de la existencia de un tratamiento discriminatorio respecto a la mujer en el ámbito familiar, se producía una contradicción legal, puesto que la Ley de adopción de 4 de julio de 1970, posibilitaba, en el párrafo primero del artículo 178 del Código civil, que además de los cónyuges, procediendo conjuntamente, pudiera adoptar plenamente cualquier persona en estado de viudedad o soltería, por lo que no existía imposibilidad de que la mujer que hubiera enviudado o no hubiera contraído matrimonio, pudiera convertirse en madre adoptiva.

Otras preferencias, en el tratamiento que el Código civil realiza en diversos preceptos, otorgan una situación de prevalencia al varón sobre la mujer ${ }^{20}$.

\subsection{Ley $11 / 1981$, de 13 de mayo y Ley $30 / 1981$, de 7 de julio}

Con la proclamación constitucional de que el hombre y la mujer tienen derecho a contraer matrimonio con plena igualdad jurídica (artículo. 32.1) se promulgaron dos leyes de gran importancia para la equiparación efectiva de marido y mujer dentro del matrimonio:

- Ley 11/1981, de 13 de mayo, sobre filiación, patria potestad y régimen económico del matrimonio.

- Ley 30/1981, de 7 de julio, reguladora del sistema matrimonial, popularmente conocida como Ley del divorcio.

La promulgación de las citadas normativas supuso la instauración de un nuevo Derecho de Familia que- según hemos expuesto en esta breve evolución histórica desde la redacción originaria del Código civil- comenzó a perfilarse a mediados de la década de los años setenta. Esta nueva consideración en la posición jurídica de la mujer en el Derecho de Familia se tradujo, en una total equiparación entre la mujer y el varón con independencia de su estado de soltería, viudedad o matrimonial.

20. En este sentido, a título de ejemplo, citaré el párrafo primero del artículo 1066 del Código civil que, en relación a los títulos de adquisición o pertenencia de una finca existiendo varios coherederos, dispone: "Cuando el mismo título comprenda varias fincas adjudicadas a diversos coherederos, o una sola que se haya dividido entre dos o más, el título quedará en poder del mayor interesado en la finca o fincas, y se facilitarán a los otros copias fehacientes, a costa del caudal hereditario. Si el interés fuere igual, el título se entregará la varón, y, habiendo más de uno, al de mayor edad». En el mismo sentido, el artículo 1060 del Código civil, disponiendo la representación de los hijos menores de edad, en la partición de la herencia, por el padre y en su caso por la madre. 
En consecuencia, en líneas generales, se procede a la sustitución de la «expresiones marido y mujer» por la de "cónyuges", salvo en aquellos preceptos que hacen referencia a la igualdad conyugal. En la nueva sistematización del Título cuarto del Libro primero del Código civil, como resultado de la novedosa normativa, se reserva el Capítulo quinto ${ }^{21}$ a los derechos y deberes de los cónyuges; estableciéndose la igualdad entre ambos, el respeto y la ayuda mutua, la obligación de vivir juntos, guardarse fidelidad y socorrerse mutuamente; asimismo fijarán de común acuerdo el domicilio conyugal. Siguiendo esta tendencia, el artículo 71 del Código civil dispone que ninguno de los cónyuges puede atribuirse la representación del otro sin que le hubiese sido conferida.

En base a estos presupuestos, además de la supresión de la dote y atribución conjunta a los padres, con independencia de su estado matrimonial ${ }^{22}$, de la patria potestad sobre sus hijos menores de edad no emancipados ${ }^{23}$, los cónyuges, a tenor de lo dispuesto en el artículo 1315 del Código civil, tendrán libertad para configurar su régimen económico matrimonial; siendo nula, a tenor del artículo 1328, cualquier estipulación limitativa de la igualdad de derechos que corresponda a cada cónyuge. En base a este planteamiento, cualquiera de los consortes queda facultado para atender a las necesidades ordinarias de la familia según dispone el artículo 1319.1 del Código civil; quedando, de esta forma, cualquiera de ellos facultado para el ejercicio de la "potestad doméstica»que tradicionalmente con bastantes limitaciones le había sido concedido a la mujer ${ }^{24}$.

La última parte del artículo 1438 del Código civil - precepto referido al régimen matrimonial de separación de bienes - es también una novedad de la reforma de 1981, puesto que, hasta ese momento, el Código civil había guardado silencio sobre las labores domésticas, a las que en muchísimos casos se dedicaba exclusivamente la mujer. Quizás, el legislador, pensando que las tareas y labores domésticas, todavía en 1981, las seguía realizando, en la mayoría de los casos, la mujer, introduce que en este régimen matrimonial sea valorado el trabajo doméstico de cualquiera de los cónyuges, disponiendo que «el trabajo para la casa será computado como contribución a las cargas y dará derecho a obtener una compensación que el Juez señalará, a falta de acuerdo, a la extin-

21. El capítulo quinto del título cuarto del libro primero del Código civil lo componen los artículos 66 al 72 inclusive; quedando este último precepto sin contenido.

22. Artículo 108/II según redacción por Ley 11/1981, de 13 de mayo: «La filiación matrimonial y la no matrimonial, así como la adoptiva, surten los mismos efectos, conforme a las disposiciones de este Código".

23. Artículo 154 párrafo primero del Código civil: «Los hijos no emancipados están bajo la potestad del padre y de la madre».

Artículo 156 párrafo primero del Código civil: «La patria potestad se ejercerá conjuntamente por ambos progenitores o por uno solo con el consentimiento expreso o tácito del otro...».

24. Artículo 62 del C.c. en su redacción originaria: «Son nulos los actos ejecutados por la mujer contra lo dispuesto en los anteriores artículos (relativos a la administración de los bienes de la sociedad conyugal), salvo cuando se trate de cosas que por su naturaleza estén destinadas al consumo ordinario de la familia, en cuyo caso las compras hechas por la mujer serán válidas. Las compras de joyas, muebles y objetos preciosos, hechas sin licencia del marido, sólo se convalidarán cuando éste hubiese consentido a su mujer el uso y disfrute de tales objetos». 
ción del régimen de separación». El resultado de esta novedosa valoración de las tareas del hogar es verdaderamente satisfactorio, puesto que no sólo se computa como contribución a las cargas matrimoniales; también como compensación a la extinción del citado régimen de separación.

A mi entender parece que el legislador quiso "premiar» tantos años de dedicación de la mujer a la ardua tarea del hogar, resultando doblemente considerado este trabajo. En cualquier caso, si bien actualmente, cualquiera de los cónyuges, en virtud de la planificación del hogar conyugal, puede elegir su dedicación a la organización del hogar familiar, no resultaría oportuno ni correcto presumir que se haya intentado que el varón, en el supuesto de encargarse de esta función, pudiese resultar en una situación discriminatoria, similar a la que en épocas pasadas aconteció con la mujer.

Siguiendo esta tendencia, la novedosa Ley 15/2005, de 8 de julio, sobre divorcio rápido y custodia compartida, introduce unos ligeros retoques en el artículo 97 del Código civil que posibilita que, cualquiera de los cónyuges que con ocasión de la separación o divorcio sufra un desequilibrio económico en relación a su consorte, tenga derecho a una compensación económica. Entre las circunstancias enumeradas en el mencionado precepto, introduce una nueva, referida a cualquier otra circunstancia relevante, lo que a mi entender puede interpretarse como un logro para la mujer en determinadas circunstancias que superen a las enunciadas en los números tercero y cuarto ${ }^{25}$.

En otro orden de cosas, por constituir un logro considerable en la evolución de la posición jurídica de la mujer en el ámbito del Derecho de familia, debe hacerse constar el avance que supuso la Ley 35/1988, de 22 de noviembre, sobre técnicas de reproducción asistida ${ }^{26}$, posibilitando su acceso como usuaria de las técnicas establecidas en la Ley con independencia de su estado civil ${ }^{27}$.

Para concluir con esta exposición que no ha tenido otra pretensión que recordar o exponer, de manera somera, la evolución de la posición jurídica de

25. Artículo. 97 del Código civil: «el cónyuge al que la separación o el divorcio produzca un desequilibrio económico en relación con la posición del otro, que implique un empeoramiento en su situación anterior en el matrimonio, tendrá derecho a una compensación que podrá consistir en una pensión temporal o por tiempo indefinido, o en una prestación única, según se determine en el convenio regulador o en la sentencia.

A falta de acuerdo de los cónyuges, el Juez, en sentencia, determinará su importe teniendo en cuenta las siguientes circunstancias:

$n^{\circ} 3$ La cualificación profesional y las probabilidades de acceso a un empleo.

$\mathrm{n}^{\circ} 4$ La dedicación pasada y futura a la familia.

$n^{\circ} 9$ Cualquier otra circunstancia relevante.»

26. Esta Ley ha sido recientemente modificada por la Ley 14/2006, de técnicas de reproducción asistida (BOE, de 27 de mayo de 2006). En cualquier caso, respecto a la temática que nos ocupa no se ha producido ningún cambio en este sentido, salvo la inclusión expresa de que para ser receptora resulta independiente el estado civil y la orientación sexual de la mujer.

27. El artículo 6 de la Ley sobre técnicas de reproducción asistida dispone en su número 1 que «toda mujer podrá ser receptora o usuaria de las técnicas reguladas en la presente Ley, siempre que haya prestado su consentimiento a la utilización de aquellas de manera libre, consciente, expresa y por escrito. Deberá tener dieciocho años al menos y plena capacidad de obrar». Si la mujer está casada, el n 3 impone el consentimiento de su marido: «Si estuviere casada, se precisará 
la mujer en el ámbito del Derecho de Familia, señalaré que salvo pequeños retoques, introducidos por la Ley 11/1990, de 15 de octubre, sobre reforma del Código civil en aplicación del principio de no discriminación por razón de sexo, con objeto de borrar discriminaciones terminológicas, es a partir de este momento -1981- cuando desaparece cualquier tipo de discriminación en la posición jurídica de la mujer en el ámbito reseñado. Haciendo constar, en cualquier caso, que tanto socialmente como en otros ámbitos legales, todavía falta la real consolidación de esa igualdad o, en sentido más correcto, equiparación ${ }^{28}$. Si bien la novedosa Ley de divorcio rápido y custodia compartida- a la que hemos hecho referencia en líneas precedentes-introduce en el artículo 68 del Código civil ${ }^{29}$, junto a la obligación de los cónyuges de vivir juntos, guardarse fidelidad y socorrerse mutuamente, la responsabilidad de ambos consortes en el ámbito doméstico y en el cuidado y atención de descendientes, ascendientes y otras personas dependientes a su cargo, la realidad nos muestra que todavía queda camino por recorrer para su asunción en el ámbito social. La misma afirmación, creo sinceramente, debe hacerse respecto a la guarda y custodia de los hijos menores de edad en los supuestos de separación o divorcio de sus progenitores ${ }^{30}$.

además el consentimiento del marido, con las características expresadas en el apartado anterior, a menos que estuvieren separados por sentencia firme de divorcio o separación, o de hecho o por mutuo acuerdo que conste fehacientemente».

28. Respecto a los progresos que en esta sede se vienen realizando, señalaré que con fecha de 19 de mayo de 2006, el Consejo General del Poder Judicial ha emitido un informe sobre el Anteproyecto de Ley Orgánica de igualdad entre mujeres y hombres. En el referido se pone de manifiesto, entre otras cuestiones, que efectivamente «la lucha por la igualdad está en la base de la construcción del Estado moderno........]Nuestra Constitución no se limitó a recoger el principio de igualdad formal (artículo. 14), propio de esa tradición constitucionalista, ni le bastó configurarlo como derecho fundamental especialmente tutelable (artículo. 53.2). Dio un paso más con el artículo 9.2. Este precepto, tomado del artículo 3.2 de la Constitución italiana, confiere un dinamismo especial al fijar, en lo que aquí interesa, el argumento de los Poderes Públicos en nuestro Estado Social y democrático de Derecho: promoción de la igualdad, remoción de los obstáculos que esa igualdad sea real y efectiva». Puede consultarse el informe al que hacemos referencia en Iustel.com de 22 de mayo de 2006.

Resulta, también, significativo en este ámbito de la consolidación a que hacíamos referencia la reciente legislación autónoma sobre mediación familiar. En este sentido, por hacer referencia, en el momento de redactar estas líneas, a la última normativa en esta temática, la Ley 1/2006, de 6 de abril, de mediación familiar de Castilla y León, (BOE de 3 de mayo), en su Exposición de Motivos pone de manifiesto que "El Estatuto de Autonomía de Castilla y León establece en su artículo 8.2 que corresponde a los poderes públicos de la Comunidad promover las condiciones para que la libertad y la igualdad del individuo y de los grupos en que se integra sean reales y efectivas, remover los obstáculos que impidan o dificulten su plenitud».

29. Artículo 68 del Código civil: «los cónyuges están obligados a vivir juntos, guardarse fidelidad y socorrerse mutuamente. Deberán, además, compartir las responsabilidades domésticas y el cuidado y atención de ascendientes y descendientes y otras personas dependientes a su cargo».

30. Resulta un dato constatable que aquellas mujeres que consienten, en los supuestos de separación o divorcio, que la custodia sobre sus hijos menores la ostente el otro progenitor, son censuradas familiar y socialmente. 
En este ámbito, por lo que respecta a nuestra Comunidad Autónoma, la reciente Ley Orgánica $1 / 2006$, de 10 de abril ${ }^{31}$ de reforma de la Ley Orgánica 5/1982, de 1 de julio, de Estatuto de Autonomía de la Comunidad Valenciana, entre otros preceptos importantes que modifica, hace una nueva redacción del artículo 11 en los siguientes términos: "La Generalitat, conforme a la Carta de los Derechos Sociales, velará en todo caso para que las mujeres y los hombres puedan participar plenamente en la vida laboral, social, familiar y política sin discriminaciones de ningún tipo y garantizarán que lo hagan en igualdad de condiciones. A estos efectos se garantizará la compatibilidad de la vida familiar y laboral». 